\title{
An improved constant evaporative fraction method for estimating daily evapotranspiration from remotely-sensed instantaneous observations
}

\author{
Ronglin Tang ${ }^{1,2}$, Zhao-Liang $\mathrm{Li}^{3,4}$
}

1. State Key Laboratory of Resources and Environment Information System, Institute of Geographic Sciences and Natural Resources Research, Beijing 100101, China

2. University of Chinese Academy of Sciences, Beijing 100049, China

3. Key Laboratory of Agri-informatics, Ministry of Agriculture/Institute of Agricultural Resources and Regional Planning, Chinese Academy of Agricultural Sciences, Beijing 100081, China

4. ICube, UdS, CNRS; 300 Boulevard Sebastien Brant, CS10413, 67412 Illkirch, France

* Authors to whom correspondence should be addressed: lizhaoliang@ caas.cn

\begin{abstract}
Evapotranspiration (ET) is a primary mechanism for water and heat transfer between land and the atmosphere. One approach to estimate ET is from instantaneous remotely-sensed data. The constant evaporative fraction (EF) method is then usually used to estimate integrated daily fluxes, which are typically underestimated values. Here, we present a theoretical improvement to the conventional EF. The improved EF is shown to be robust and superior to the conventional approach and it significantly reduces the underestimation bias.
\end{abstract}

Key words: Evapotranspiration, Constant evaporative fraction method, Remote sensing

\section{Introduction}

Evapotranspiration (ET) is a primary mechanism for water and heat transfer between land and the atmosphere. In recent decades, a great number of models with varying degrees of complexity and accuracy (see the ET reviews of Li et al. [2009] and Kalma et al. [2008]) have been developed to estimate regional ET using remote sensing technology. However, these remote sensing models generally provide only instantaneous snapshots of ET at discrete satellite overpass times which are not sufficient to meet the needs of researchers who often require accurate estimates of ET at daily and longer timescales. The most common technique for converting instantaneous ET estimates to daily timescales is based on the assumption of a constant evaporative fraction (EF), defined as the ratio of the latent heat flux (LE) to available energy $\left(\mathrm{R}_{\mathrm{n}}-\mathrm{G}\right)$ [Brutsaert and Sugita, 1992; Nichols 
and Cuenca, 1993; Crago, 1996; Gómez et al., 2005; Gentine et al., 2007; Sobrino et al., 2007; Galleguillos et al., 2011]. However, numerous studies [Tang et al., 2013; Van Niel et al., 2011; Cammalleri et al., 2012; Delogu et al., 2012; Xu et al., 2015; Cha'vez et al., 2008] have reported that daily ET estimates are significantly underestimated by up to 34\% [Van Niel et al., 2012] when the EF method is applied.

The objectives of this paper are twofold: 1) to develop an improved constant EF method via a theoretical derivation to convert remote-sensing based instantaneous ET to a daily scale and 2) to test the robustness of the improved constant EF method using ground-based ET measurements and four datasets of remote-sensing based instantaneous ET. Section 2 presents the rationale of the conventional and improved constant EF methods. Section 3 provides a brief introduction of the surface meteorological and energy flux measurements and the remote sensing ET datasets. Section 4 describes the results of the evaluation of the conventional and improved constant EF methods. Finally, the conclusions are presented in Section 5.

\section{Methodology}

\subsection{Conventional constant evaporative fraction method}

For the conventional constant evaporative fraction method, assuming that the instantaneous EF equals the daily $\mathrm{EF}\left(\mathrm{EF}_{\mathrm{i}}=\mathrm{EF}_{\mathrm{d}}\right)$, the daily $\mathrm{LE}$ can be derived as follows:

$$
L E_{d}=E F_{d}\left(R_{n}-G\right)_{d}=\frac{L E_{i}}{\left(R_{n}-G\right)_{i}}\left(R_{n}-G\right)_{d}
$$

where $R_{n}$ is the surface net radiation, $\mathrm{W} / \mathrm{m}^{2}$, and $G$ is the soil heat flux, $\mathrm{W} / \mathrm{m}^{2}$. The subscripts i and $\mathrm{d}$ indicate the value at the instantaneous and daily time scales, respectively.

\subsection{Improved constant evaporative fraction method}

By rearranging the Penman-Monteith equation, surface evapotranspiration (or latent heat flux) can be mathematically expressed with the following equations [McNaughton and Jarvis, 1983; Pereira, 2004]:

$$
\begin{gathered}
L E=\alpha \frac{\Delta}{\Delta+\gamma}\left(R_{n}-G\right) \\
\alpha=\Omega / \Omega^{*}
\end{gathered}
$$




$$
\begin{gathered}
\Omega=\frac{1}{1+\frac{\gamma}{\Delta+\gamma} \frac{r_{c}}{r_{a}}} \\
\Omega^{*}=\frac{1}{1+\frac{\gamma}{\Delta+\gamma} \frac{r^{*}}{r_{a}}} \\
r^{*}=\frac{(\Delta+\gamma) \rho C_{p} V P D}{\Delta \gamma\left(R_{n}-G\right)}
\end{gathered}
$$

where $\Delta$ is the slope of the saturated vapor pressure versus the air temperature curve, $\mathrm{kPa} /{ }^{\circ} \mathrm{C} ; \gamma$ is the psychrometric constant, $\mathrm{kPa} /{ }^{\circ} \mathrm{C} ; \Omega$ is the decoupling factor and represents the relative contribution of the radiative and aerodynamic terms to the overall ET. Additionally, $r^{*}$ is the critical surface resistance when LE equals equilibrium evapotranspiration, $\mathrm{s} / \mathrm{m} ; r_{a}$ is the aerodynamic resistance, $\mathrm{s} / \mathrm{m} ; r_{c}$ is the surface resistance, $\mathrm{s} / \mathrm{m} ; \rho$ is the air density, $\mathrm{kg} / \mathrm{m}^{3} ; C_{p}$ is the specific heat of the air, $\mathrm{J} /\left(\mathrm{kg} \cdot{ }^{\circ} \mathrm{C}\right)$; and $V P D$ is the vapor pressure deficit of the air, $\mathrm{kPa}$. Given that Eqs. (2-6) are valid and can be applied at both instantaneous and daily time scales [Allen et al., 1998; ASCE-EWRI, 2005], the daily LE can be theoretically linked to instantaneous EF and daily surface available energy with the following equation:

$$
\begin{aligned}
L E_{d} & =\frac{L E_{i}}{\left(R_{n}-G\right)_{i}}\left(R_{n}-G\right)_{d} \frac{\Delta_{d}}{\Delta_{d}+\gamma} \frac{\Delta_{i}+\gamma}{\Delta_{i}} \frac{\alpha_{d}}{\alpha_{i}} \\
& =\frac{L E_{i}}{\left(R_{n}-G\right)_{i}}\left(R_{n}-G\right)_{d} \frac{\Delta_{d}}{\Delta_{d}+\gamma} \frac{\Delta_{i}+\gamma}{\Delta_{i}} \frac{\Omega_{i}^{*}}{\Omega_{d}^{*}} \frac{\Omega_{d}}{\Omega_{i}}
\end{aligned}
$$

In the improved constant evaporative fraction method, to achieve a tradeoff between model complexity and accuracy, $\Omega$ is assumed to be constant during the day $\left(\Omega_{\mathrm{d}}=\Omega_{\mathrm{i}}\right)$ [Goldberg and Bernhofer, 2001] and the daily LE can be expressed as follows:

$$
\left(L E_{d}\right)_{\text {improve }}=\frac{L E_{i}}{\left(R_{n}-G\right)_{i}}\left(R_{n}-G\right)_{d} \frac{\Delta_{d}}{\Delta_{d}+\gamma} \frac{\Delta_{i}+\gamma}{\Delta_{i}} \frac{\Omega_{i}^{*}}{\Omega_{d}^{*}}=\left(L E_{d}\right)_{\text {conv }} \frac{\Delta_{d}}{\Delta_{d}+\gamma} \frac{\Delta_{i}+\gamma}{\Delta_{i}} \frac{\Omega_{i}^{*}}{\Omega_{d}^{*}}
$$

where $\left(L E_{d}\right)_{\text {improve }}$ is the improved daily LE and $\left(L E_{d}\right)_{\text {conv }}$ is the daily LE estimated from Eq. (1) using the conventional constant EF method. For simplicity, $r_{a}$ is calculated by assuming that the atmosphere is under neutral conditions (i.e., no stability correction function is applied). The improved constant EF method is more physically based than the conventional constant EF method and is expected to outperform it. Inputs for the improved method primarily include the instantaneous evaporative fraction, instantaneous and daily air temperature, wind speed, vapor 
pressure deficit, slope of vapor pressure, and surface available energy. Daily values of air temperature, wind speed, vapor pressure, and surface available energy are computed as the average of multiple (48 half-hourly in this study) measurements from 0:00 h to 24:00 h local time. The daily slope of the vapor pressure curve is estimated using daily air temperature. Daily VPD is computed as daily saturated vapor pressure (estimated using daily air temperature) minus daily air vapor pressure. Note that a fixed psychrometric constant $\left(0.067 \mathrm{kPa} /{ }^{\circ} \mathrm{C}\right)$ is used in Eqs. (7-8), primarily because a preliminary analysis suggested that using a variable psychrometric constant (as a function of temperature, humidity, and pressure) does not significantly improve the validation of daily ET compared to using a fixed psychrometric constant.

\section{Test site and data}

The Yucheng station $\left(36.8291^{\circ} \mathrm{N} / 116.5703^{\circ} \mathrm{E}\right)$, which is located on the North China plain, is characterized by sandy loam soil and a subhumid and monsoon climate, with a mean annual temperature and precipitation of $13.1^{\circ} \mathrm{C}$ and $528 \mathrm{~mm}$, respectively. Winter wheat is rotated with summer corn at this station. Half-hourly measurements of surface meteorological and energy flux variables, including wind speed, relative humidity, air temperature, atmospheric pressure, surface 4-component radiation (downwelling and upwelling shortwave and longwave radiation), soil heat flux, sensible heat flux and latent heat flux from the eddy covariance (EC) system, which are regularly measured at the Yucheng station, were collected from late April 2009 to late October 2011 for analysis in this study. The specifics of the sensors, the sensor deployment, and the post-processing of turbulent flux measurements can be found in Tang et al. [2011, 2013] and elsewhere. The daily latent heat flux for the validation was computed as the average of 48 half-hourly EC measurements from 0:00 $\mathrm{h}$ to 24:00 $\mathrm{h}$ local time.

Four reliable datasets of remote-sensing based instantaneous $L E$ and $R_{n}-G$ at the Yucheng station, which were estimated separately from two typical single- and dual-source energy balance models in our previous studies [Tang et al., 2011, 2013], are extracted to evaluate the performances of the conventional and improved EF methods in practical applications in this study. Specifically, these datasets are MODIS-based estimates of instantaneous LE and $R_{n}-G$ using the N95 [Norman et al., 1995] two-source model and the surface energy balance system [SEBS, Su, 2002] model for 33 clear-sky TERRA overpass times between late April 2009 and late September 
2009 and using the N95 [Norman et al., 1995] two-source model for 55 clear-sky TERRA overpass times and 46 clear-sky AQUA overpass times between late April 2009 and late October 2011. These datasets have been proven to reasonably agree with the ground-based measurements. When validated against ground-based large-aperture scintillometer-derived LE, positive biases of $1 \mathrm{~W} / \mathrm{m}^{2}$ and $35 \mathrm{~W} / \mathrm{m}^{2}$ and RMSEs of $42 \mathrm{~W} / \mathrm{m}^{2}$ and $56 \mathrm{~W} / \mathrm{m}^{2}$ were found in the N95-estimated LE and SEBS-estimated LE, respectively (see Fig. 10b in the work of Tang et al. [2011]). Similarly, positive and negative biases of $16 \mathrm{~W} / \mathrm{m}^{2}$ and $-1 \mathrm{~W} / \mathrm{m}^{2}$ and RMSEs of $46 \mathrm{~W} / \mathrm{m}^{2}$ and $34 \mathrm{~W} / \mathrm{m}^{2}$ were found in the N95-estimated LE at TERRA and AQUA overpass times, respectively (see Fig. 8c in the work of Tang et al. [2013]). These statistical results fall in between the generally acceptable upper and lower ranges of bias and RMSE. Different magnitudes of model-estimation bias and error in these three datasets are especially helpful and valuable for testing the robustness/superiority of the improved constant EF method relative to the conventional constant EF method. Please refer to Tang et al. [2011] and Tang et al. [2013] for details on the estimation methods for these instantaneous $L E$ and $\mathrm{R}_{\mathrm{n}}-\mathrm{G}$ values.

In view of the fact that remotely-sensed surface energy balance-based ET models by definition enforce an energy balance among the energy flux components, the widely applied Bowen ratio (BR) correction method and the residual energy (RE) correction method [Twine et al., 2000] are introduced in this study to close the energy imbalance between the sum of the eddy covariance (EC) system-measured sensible heat flux, latent heat flux and surface available energy. To determine whether the energy imbalance correction influences the consistency of the model performance, evaluation of the constant EF method and the improved method with the in situ EC measurements is conducted under uncorrected and corrected energy imbalance conditions.

\section{Results and discussion}

Fig. 1 presents the performances of the conventional and improved constant EF methods in converting half-hourly LE measurements at 10:30 (corresponding to the MODIS/TERRA daytime overpass time) and 13:30 (corresponding to the MODIS/AQUA daytime overpass time) local time to the daily scale. These conversions were made over 403 days between late April 2009 and late October 2011 (one day on which the performance of conventional constant EF method was very significantly deteriorated due to the very small instantaneous $R_{n}-G$ at 10:30 leading to a very large 
instantaneous EF was excluded from the 404 quality- and completeness-controlled days; see Section of 3.1 of Tang et al. [2013] for a discussion of how these 404 days were screened). Using the paired-t test (null hypothesis: the mean of the estimated daily LE from the improved EF method is equal to that from the conventional EF method; alternative hypothesis: the two statistics are not equal, at the 0.01 level of significance), the daily LE estimated using the improved EF method is shown to be statistically significantly different from that using the conventional EF method under both uncorrected and corrected energy imbalance conditions. Underestimation of the daily LE was generally found in both the conventional and our proposed EF methods. However, both the bias and the root mean square error (RMSE), as tabulated in Table 1, decreased by $>31 \%$ and $17 \%-29 \%$, respectively, when our proposed EF method was applied for the half-hourly LE conversion instead of the conventional EF method. The change in the bias demonstrated that the daily LE underestimation often found in the conventional constant EF method was overall significantly smaller for our improved method. It could be concluded that our proposed method outperformed the conventional constant EF method when the acquired instantaneous LE or half-hourly LE corresponding to the daytime overpass times of most polar-orbiting satellites was provided without any bias for conversion to the daily scale, regardless of whether the ground-based EC measurements used for truth validation were uncorrected or corrected for energy imbalance using the BR and RE methods.

In the conversion of four separately acquired datasets of MODIS-based instantaneous LE estimates from the single-source SEBS or dual-source N95 model to the daily scale, our proposed EF method also overall produced lower bias and RMSE values than the conventional constant EF method, as illustrated in Figs. 2-3 and Tables 2-3. Our proposed method performed much better than the conventional method, with a relatively large RMSE decrease of 42\%-54\% (see Fig. 2 and Table 2), when the remote-sensing based instantaneous $L E$ and $R_{n}-G$ datasets were from the work of Tang et al. [2011]. The positive biases in the SEBS-derived instantaneous LE from Tang et al. [2011] and N95-derived LE at TERRA overpass times from Tang et al. [2013] contributed in part to the positive biases in daily LE estimated using our proposed EF method. Underestimation of daily LE was still found in the conventional constant EF method. Overall, when applied to convert remote-sensing based instantaneous LE (with a certain degree of bias compared to the ground measurement) acquired at MODIS/TERRA and MODIS/AQUA overpass times to the daily scale, 
our proposed method also outperformed the conventional constant EF method.

Some analysis of the performances of the two EF methods is performed here. The EF method builds on the assumption of a constant EF and as a result allows the daily ET to be determined directly from the daily surface available energy. The improved method (assuming $\Omega_{\mathrm{d}}=\Omega_{\mathrm{i}}$ ), developed through a theoretical derivation from the physics-based Penman-Monteith equation, considers the non-linear effect of meteorological factors on the ET. The most novel aspect of this study lies in that the factor $\beta\left(=\frac{\Delta_{d}}{\Delta_{d}+\gamma} \frac{\Delta_{i}+\gamma}{\Delta_{i}} \frac{\Omega_{i}^{*}}{\Omega_{d}^{*}} \frac{\Omega_{d}}{\Omega_{i}}\right)$ in the improved method adjusts for the relative difference between the instantaneous evaporative fraction at the time of the overpass and the evaporative fraction during other timeframes. In essence, the improved method relaxes the assumption of a constant evaporative fraction, and $\beta$ can be interpreted as a correction for the $\mathrm{EF}$ method (daily ET in the improved method equals that in the EF method multiplied by the correction factor $\beta)$.

The EF method (Eq. (1)) for the conversion of instantaneous LE is a much reduced form of Eq. (7) (i.e., $\beta=1$ ). It is evident that the performance of the conventional constant EF method depends on the magnitude of the $\beta$ factor. For $\beta=1$, the conventional constant $E F$ method will produce the estimated daily LE without a bias. For $\beta>1$, an underestimation in the estimated daily LE will be produced using the conventional constant EF method. For $\beta<1$, an overestimation in the estimated daily LE will be produced. The underestimation in the estimated daily LE found by a number of authors in previous studies and in this study indicates $\beta>1$ in most cases. In fact, lots of studies report that the EF generally exhibits on a concave-up shape during the daytime, leading to the underestimation of daily ET when using the EF acquired close to noon as a constant for temporal conversion. The improved constant EF method based on simplifying the calculation of the $\beta$ factor can evidently improve the estimated daily LE that is often underestimated using the conventional constant EF method, which is expected.

It has to be mentioned that the conversion of instantaneous ET to the daily scale is performed for the same day primarily because of 1) the daily revisit period of the MODIS sensor that provides widely applied land products and 2) the possibly decreased validity of the constancy assumption made in the conversion methods over a longer time scale [Alfieri et al., 2017]. The effectiveness of the improved method during subsequent days is beyond the scope of this paper 
and is therefore not investigated in the current study. The strengths of the improved method are its more solid physical foundation and the resulting higher accuracy of the estimated daily ET than the conventional EF method. The limitation lies in the requirement of instantaneous and daily ground-based meteorological data (air temperature, VPD, and wind speed), which may be unavailable, as inputs. In practical/operational applications, these inputs, which may come from the reanalysis data estimated using numerical weather prediction models and global climate models, can introduce a certain degree of uncertainties in the estimated daily ET. A sensitivity analysis of the improved EF method using data shown in Fig. $1 \mathrm{~b}$ shows that a perturbation of $1{ }^{\circ} \mathrm{C}$ in air temperature (or a perturbation of $20 \%$ in VPD/wind speed or $10 \%$ in surface available energy) on average results in a variation of $3.5 \%(1.8 \% / 1.9 \%$ or $0.9 \%$, respectively) in the estimated daily LE.

\section{Conclusions}

In this paper, a new constant $\mathrm{EF}$ method is proposed through a theoretical derivation to improve the conversion of remote-sensing based instantaneous LE to the daily scale. The improved constant EF method is more physically based and can be applied operationally without too much model complexity and consumption of computation time. It can significantly reduce the underestimation of the daily LE estimated using the conventional constant EF method. The lower bias and RMSE in the conversion results of both ground-based half-hourly LE without any bias and remote-sensing based instantaneous LE with certain degrees of biases in this study demonstrate the great robustness of the improved constant EF method and its superiority over the conventional constant EF method. This improved method can be used instead of the conventional constant EF method to more accurately convert remote-sensing based instantaneous LE estimates to the daily scale. 

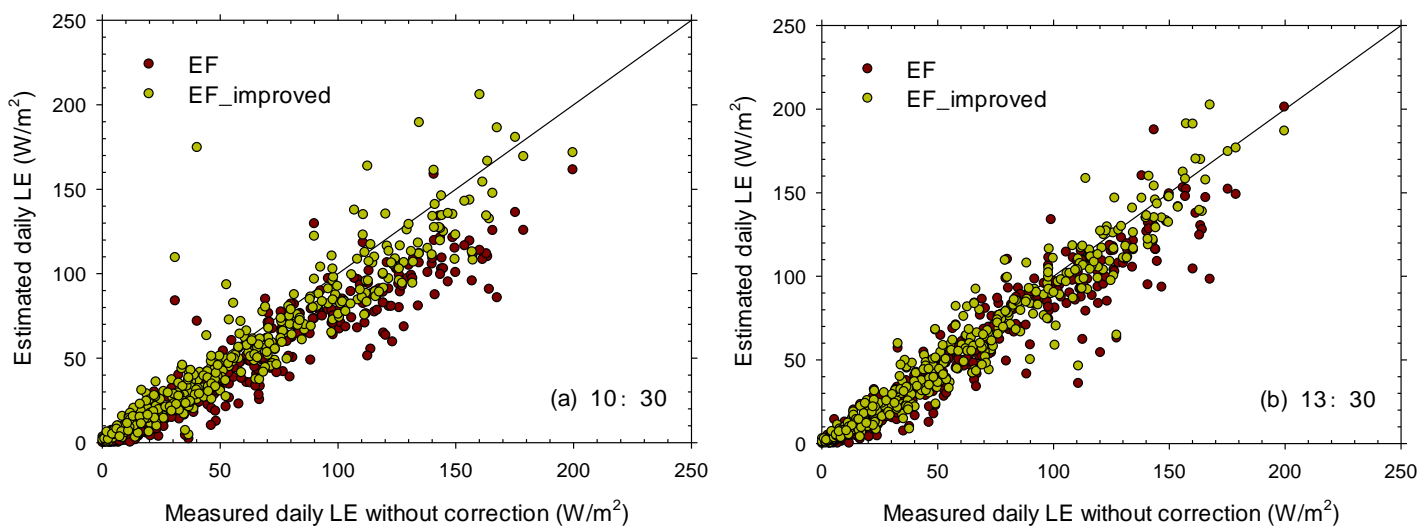

Measured daily LE without correction $\left(\mathrm{W} / \mathrm{m}^{2}\right)$
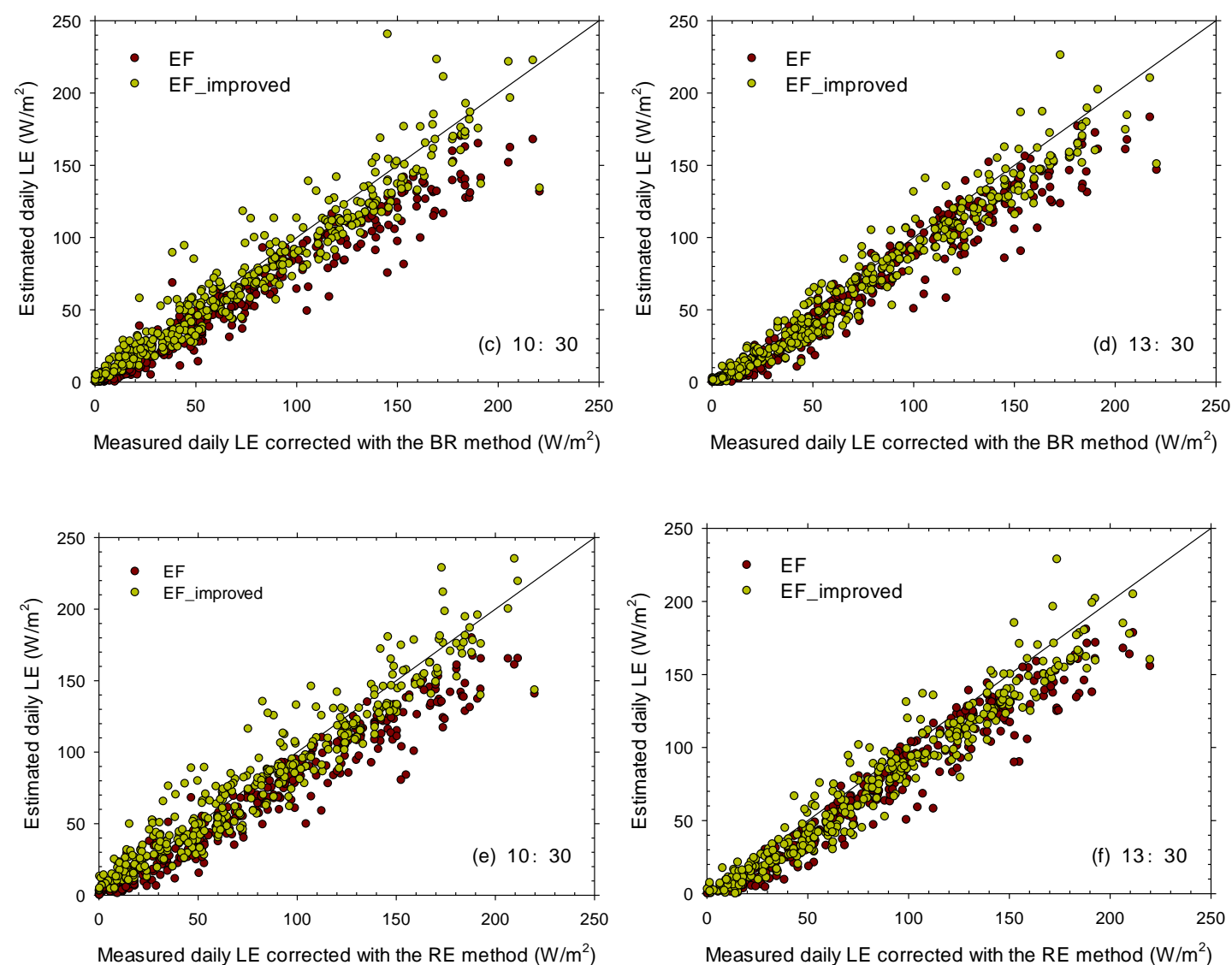

Figure 1. Comparison of daily LE estimated using the conventional and improved constant EF methods with ground-based EC measurements without an energy imbalance correction and with an energy imbalance correction based on the Bowen ratio (BR) and residual energy (RE) methods. (a), (c), and (e) Converting half-hourly measurements at 10:30 local time to the daily scale. (b), (d), and (f) Converting half-hourly measurements at 13:30 local time to the daily scale. 

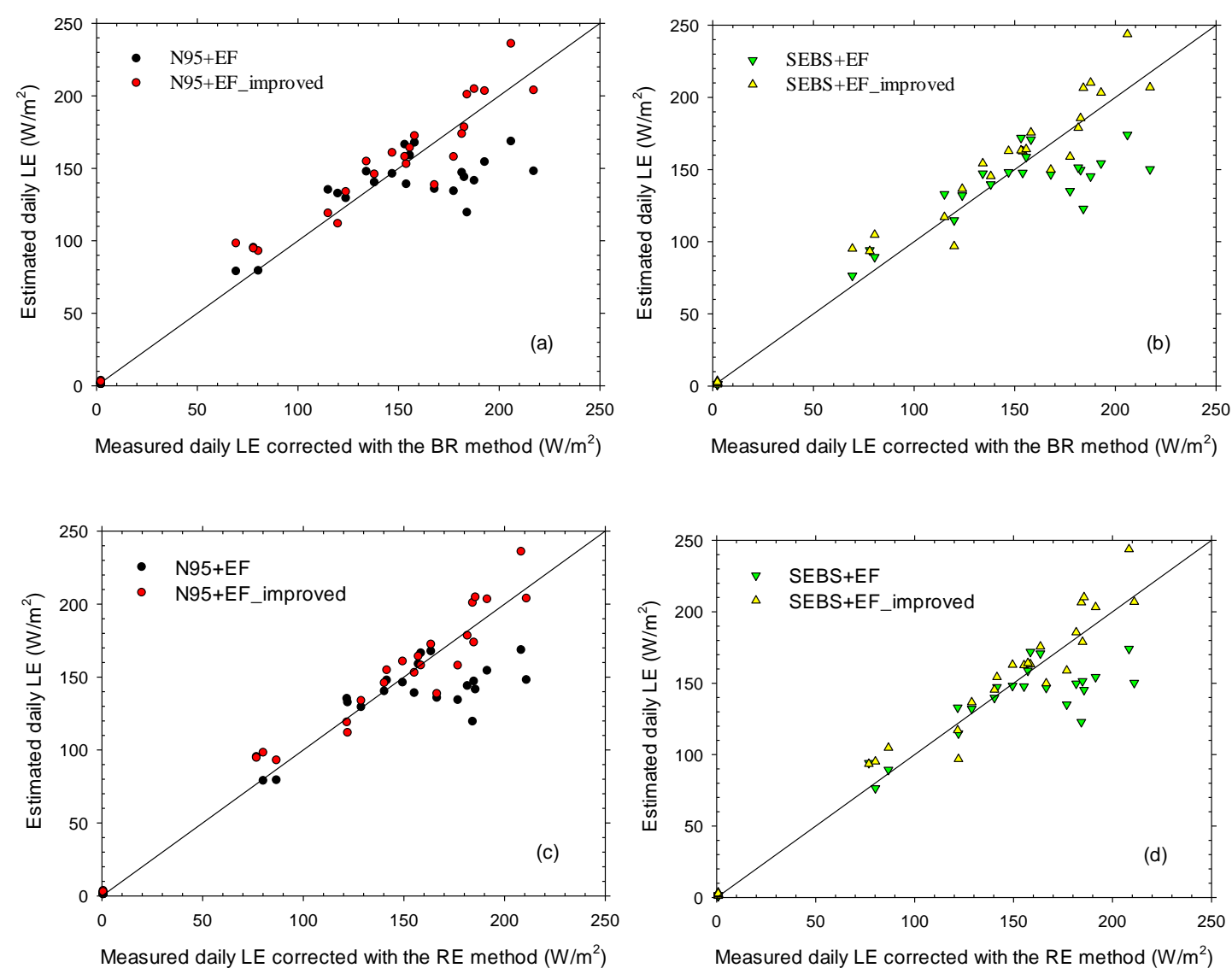

Figure 2. Comparison of daily LE estimated using two remotely-sensed datasets (the N95- and SEBS-derived instantaneous LE at MODIS/TERRA overpass times from Tang et al. [2011]) and the conventional and improved constant EF methods with ground-based EC measurements corrected with the (a-b) Bowen ratio (BR) and (c-d) residual energy (RE) methods. 

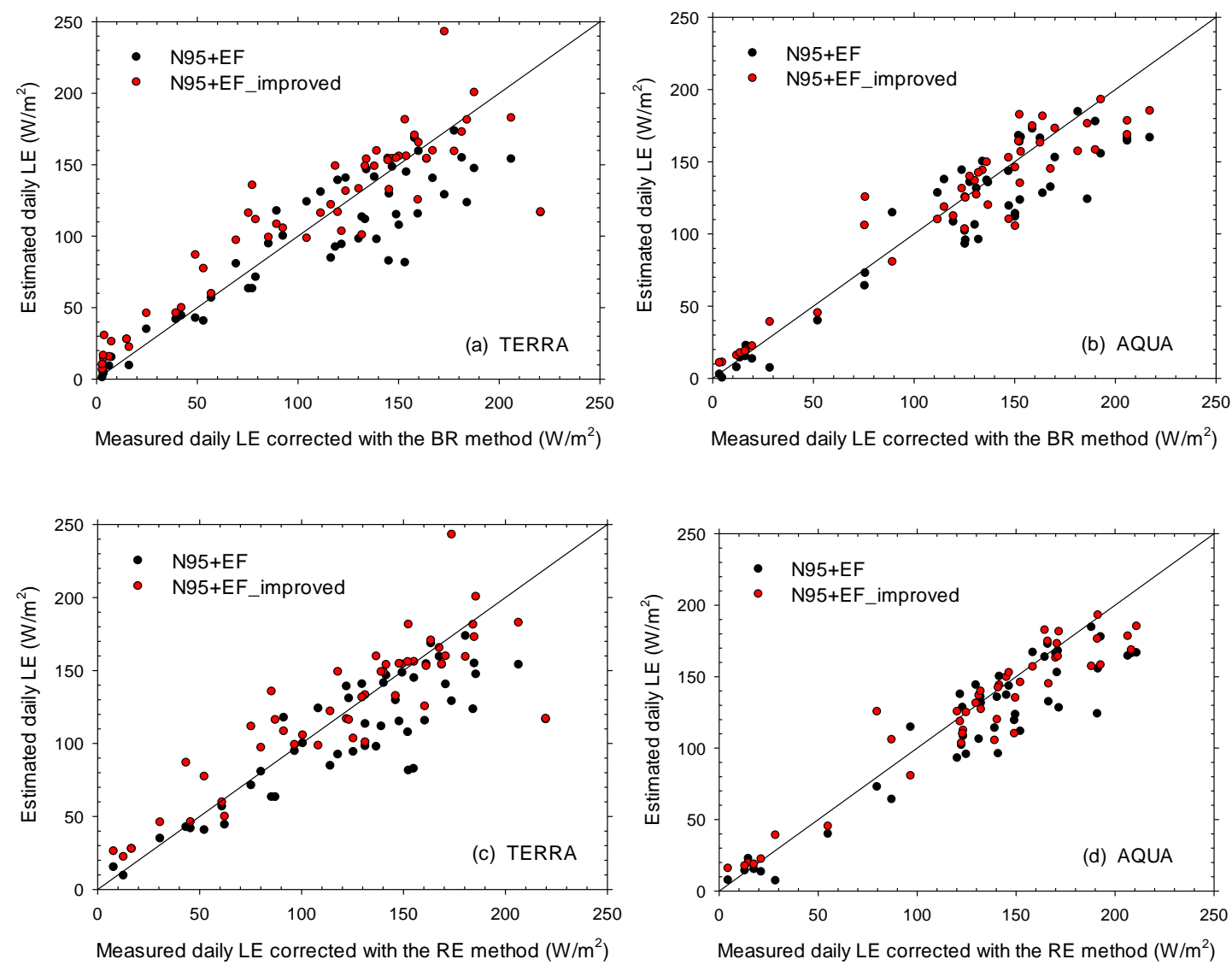

Figure 3. Comparison of daily LE estimated using two remotely-sensed datasets (the N95-derived instantaneous LE at the MODIS/TERRA and MODIS/AQUA overpass times from Tang et al. [2013]) and the conventional and improved constant EF methods with ground-based EC measurements corrected with the (a-b) Bowen ratio (BR) and (c-d) residual energy (RE) methods. 
Table 1. Statistical measures of the performances of conventional and improved constant EF methods in the conversion of half-hourly LE measurements at 10:30 and 13:30 local time to the daily scale. $\bar{O}$ is the mean of the daily EC measurements without correction or with corrections based on the BR and RE methods.

\begin{tabular}{|c|c|c|c|c|c|c|c|c|c|}
\hline & \multirow{3}{*}{$\begin{array}{c}\bar{O} \\
\left(\mathrm{~W} / \mathrm{m}^{2}\right)\end{array}$} & \multicolumn{4}{|c|}{ 10:30 } & \multicolumn{4}{|c|}{$13: 30$} \\
\hline & & \multicolumn{2}{|c|}{$\mathrm{EF}$} & \multicolumn{2}{|c|}{ EF_improved } & \multicolumn{2}{|c|}{$\mathrm{EF}$} & \multicolumn{2}{|c|}{ EF_improved } \\
\hline & & $\begin{array}{l}\text { BIAS } \\
\left(\mathrm{W} / \mathrm{m}^{2}\right)\end{array}$ & $\begin{array}{l}\text { RMSE } \\
\left(\mathrm{W} / \mathrm{m}^{2}\right)\end{array}$ & $\begin{array}{l}\text { BIAS } \\
\left(\mathrm{W} / \mathrm{m}^{2}\right)\end{array}$ & $\begin{array}{l}\text { RMSE } \\
\left(\mathrm{W} / \mathrm{m}^{2}\right)\end{array}$ & $\begin{array}{l}\text { BIAS } \\
\left(\mathrm{W} / \mathrm{m}^{2}\right)\end{array}$ & $\begin{array}{l}\text { RMSE } \\
\left(\mathrm{W} / \mathrm{m}^{2}\right)\end{array}$ & $\begin{array}{l}\text { BIAS } \\
\left(\mathrm{W} / \mathrm{m}^{2}\right)\end{array}$ & $\begin{array}{l}\text { RMSE } \\
\left(\mathrm{W} / \mathrm{m}^{2}\right)\end{array}$ \\
\hline EC & 57 & -15 & 22 & -6 & 16 & -9 & 16 & -5 & 12 \\
\hline BR & 69 & -15 & 21 & -3 & 15 & -12 & 17 & -7 & 13 \\
\hline RE & 72 & -13 & 20 & 0 & 16 & -13 & 18 & -9 & 15 \\
\hline
\end{tabular}

Table 2. Statistical measures of the performances of conventional and improved constant EF methods in the conversion of two datasets (N95- and SEBS-derived instantaneous LE at TERRA overpass times from Tang et al. [2011]) to the daily scale. $\bar{O}$ is the mean of the daily EC measurements corrected with the BR and RE methods.

\begin{tabular}{|c|c|c|c|c|c|c|c|c|c|}
\hline & \multirow{3}{*}{$\begin{array}{c}\bar{O} \\
\left(\mathrm{~W} / \mathrm{m}^{2}\right)\end{array}$} & \multicolumn{4}{|c|}{ N95 } & \multicolumn{4}{|c|}{ SEBS } \\
\hline & & \multicolumn{2}{|c|}{$\mathrm{EF}$} & \multicolumn{2}{|c|}{ EF_improved } & \multicolumn{2}{|c|}{$\mathrm{EF}$} & \multicolumn{2}{|c|}{ EF_improved } \\
\hline & & $\begin{array}{l}\text { BIAS } \\
\left(\mathrm{W} / \mathrm{m}^{2}\right)\end{array}$ & $\begin{array}{l}\text { RMSE } \\
\left(\mathrm{W} / \mathrm{m}^{2}\right)\end{array}$ & $\begin{array}{l}\text { BIAS } \\
\left(\mathrm{W} / \mathrm{m}^{2}\right)\end{array}$ & $\begin{array}{l}\text { RMSE } \\
\left(\mathrm{W} / \mathrm{m}^{2}\right)\end{array}$ & $\begin{array}{l}\text { BIAS } \\
\left(\mathrm{W} / \mathrm{m}^{2}\right)\end{array}$ & $\begin{array}{l}\text { RMSE } \\
\left(\mathrm{W} / \mathrm{m}^{2}\right)\end{array}$ & $\begin{array}{l}\text { BIAS } \\
\left(\mathrm{W} / \mathrm{m}^{2}\right)\end{array}$ & $\begin{array}{l}\text { RMSE } \\
\left(\mathrm{W} / \mathrm{m}^{2}\right)\end{array}$ \\
\hline $\mathrm{BR}$ & 101 & -10 & 25 & 4 & 13 & -8 & 24 & 6 & 14 \\
\hline $\mathrm{RE}$ & 102 & -11 & 24 & 3 & 11 & -9 & 23 & 5 & 13 \\
\hline
\end{tabular}

Table 3. Same as Table 2, but for the two datasets of N95-derived instantaneous LE at TERRA and AQUA overpass times from Tang et al. [2013].

\begin{tabular}{|c|c|c|c|c|c|c|c|c|c|c|}
\hline & \multicolumn{5}{|c|}{ TERRA } & \multicolumn{5}{|c|}{ AQUA } \\
\hline & \multirow{2}{*}{$\begin{array}{c}\bar{O} \\
\left(\mathrm{~W} / \mathrm{m}^{2}\right)\end{array}$} & \multicolumn{2}{|c|}{$\mathrm{EF}$} & \multicolumn{2}{|c|}{ EF_improved } & \multirow{2}{*}{$\begin{array}{c}\bar{O} \\
\left(\mathrm{~W} / \mathrm{m}^{2}\right)\end{array}$} & \multicolumn{2}{|c|}{$\mathrm{EF}$} & \multicolumn{2}{|c|}{ EF_improved } \\
\hline & & $\begin{array}{l}\text { BIAS } \\
\left(\mathrm{W} / \mathrm{m}^{2}\right)\end{array}$ & $\begin{array}{l}\text { RMSE } \\
\left(\mathrm{W} / \mathrm{m}^{2}\right)\end{array}$ & $\begin{array}{l}\text { BIAS } \\
\left(\mathrm{W} / \mathrm{m}^{2}\right)\end{array}$ & $\begin{array}{l}\text { RMSE } \\
\left(\mathrm{W} / \mathrm{m}^{2}\right)\end{array}$ & & $\begin{array}{l}\text { BIAS } \\
\left(\mathrm{W} / \mathrm{m}^{2}\right)\end{array}$ & $\begin{array}{l}\text { RMSE } \\
\left(\mathrm{W} / \mathrm{m}^{2}\right)\end{array}$ & $\begin{array}{l}\text { BIAS } \\
\left(\mathrm{W} / \mathrm{m}^{2}\right)\end{array}$ & $\begin{array}{l}\text { RMSE } \\
\left(\mathrm{W} / \mathrm{m}^{2}\right)\end{array}$ \\
\hline $\mathrm{BR}$ & 106 & -13 & 29 & 10 & 30 & 122 & -11 & 24 & -2 & 19 \\
\hline $\mathrm{RE}$ & 108 & -15 & 30 & 8 & 29 & 124 & -14 & 24 & -4 & 18 \\
\hline
\end{tabular}




\section{Acknowledgments}

The staff members at the Yucheng site are acknowledged for their hard work with the setup and maintenance of the ground-based instruments and data collection. Associate Professor Yuanyuan Jia and Professor Chuanrong Li in the Academy of Opto-Electronics, Chinese Academy of Sciences, are thanked for their cooperation in providing the surface measurements. This work was partly supported by the National Natural Science Foundation of China under Grant 41571351 and 41571367 and by the International Science \& Technology Cooperation Program of China under Grant 2014DFE10220.

\section{References}

Alfieri, J. G, M. C. Anderson, W. P. Kustas, and C. Cammalleri (2017), Effect of the revisit interval and temporal upscaling methods on the accuracy of remotely sensed evapotranspiration estimates, Hydrol. Earth Syst. Sci., 21, 83-98.

Allen, R. G., L. S. Pereira, D. Raes, and M. Smith (1998), Crop evapotranspiration-Guidelines for computing crop water requirements, FAO Technical Paper 56, Food and Agricultural Organization of the United Nations, Rome, 300(9), D05109.

ASCE-EWRI. (2005), The ASCE Standardized Reference Evapotranspiration Equation. Technical Committee report to the Environmental and Water Resources Institute of the American Society of Civil Engineers from the Task Committee on Standardization of Reference Evapotranspiration, ASCE-EWRI, 1801 Alexander Bell Drive, Reston, VA 20191-4400, 173 pp, doi:10.1061/40499(2000)126.

Brutsaert, W., and M. Sugita (1992), Application of self-preservation in the diurnal evolution of the surface energy budget to determine daily evaporation, J. Geophys. Res. Atmos., 97, 18377-18382, doi:10.1029/92JD00255.

Cammalleri, C., M. C. Anderson, G. Ciraolo, G. D’Urso, W. P. Kustas, G. La Loggia, and M. Minacapilli (2012), Applications of a remote sensing-based two-source energy balance algorithm for mapping surface fluxes without in situ air temperature observations, Remote Sens. Environ., 124, 502-515, doi:10.1016/j.rse.2012.06.009.

Chávez, J. L., C. M. Neale, J. H. Prueger, and W. P. Kustas (2008), Daily evapotranspiration estimates from extrapolating instantaneous airborne remote sensing ET values, Irrigation Sci., 27, 67-81, doi:10.1007/s00271-008-0122-3.

Crago, R. (1996), Conservation and variability of the evaporative fraction during the daytime, $J$. Hydrol., 180, 173-194, doi:10.1016/0022-1694(95)02903-6.

Delogu, E., G. Boulet, A. Olioso, B. Coudert, J. Chirouze, E. Ceschia, V. Le Dantec, O. Marloie, G. Chehbouni, and J. P. Lagouarde (2012), Reconstruction of temporal variations of evapotranspiration using instantaneous estimates at the time of satellite overpass, Hydrol. Earth Syst. Sci., 16, 2995-3010, doi:10.5194/hess-16-2995-2012.

Galleguillos, M., F. Jacob, L. Prévot, P. Lagacherie, and S. Liang (2011), Mapping Daily Evapotranspiration Over a Mediterranean Vineyard Watershed, IEEE Geosci. Remote Sens. Lett., 8(1), 168-172, doi:10.1109/LGRS.2010.2055230. 
Gentine P., D. Entekhabi, A. Chehbouni, G. Boulet, and B. Duchemin (2007), Analysis of evaporative fraction diurnal behavior, Agricult. Forest Meteorol., 143(1-2), 13-29, doi:10.1016/j.agrformet.2006.11.002.

Goldberg, V., and Ch. Bernhofer (2001), Quantifying the coupling degree between land surface and the atmospheric boundary layer with the coupled vegetation-atmosphere model HIRVAC, Ann. Geophys., 19 (5), 581-587, doi:10.5194/angeo-19-581-2001.

Gómez, M., A. Olioso, J. Sobrino, and F. Jacob (2005), Retrieval of evapotranspiration over the Alpilles/ReSeDA experimental site using airborne POLDER sensor and a thermal camera, Remote Sens. Environ., 96(3/4), 399-408, doi:10.1016/j.rse.2005.03.006.

Kalma, J. D., T. R. McVicar, and M. F. McCabe (2008), Estimating land surface evaporation: a review of methods using remotely sensed surface temperature data, Surv. Geophys., 29, 421-469, doi:10.1007/s10712-008-9037-z.

Li, Z. -L., R. L. Tang, Z. Wan, Y. Bi, C. Zhou, B. Tang, G. Yan, and X. Zhang (2009), A Review of current methodologies for regional evapotranspiration estimation from remotely sensed data, Sensors, 9, 3801-3853, doi:10.3390/s90503801.

McNaughton, K.G., and P.G. Jarvis (1983), Predicting effects of vegetation changes on transpiration and evaporation. In: Kozlowski, T.T. (Ed.), Water Deficits and Plant Growth, vol. VII. Academic Press, 1-47.

Nichols, W. E., and R. H. Cuenca (1993), Evaluation of the evaporative fraction for parameterization of the surface energy balance, Water Resour. Res., 29(11), 3681-3690, doi:10.1029/93WR01958.

Norman, J. M., W. P. Kustas, and K. S. Humes (1995), A two-source approach for estimating soil and vegetation energy fluxes from observations of directional radiometric surface temperature, Agricult. Forest Meteorol., 77, 263-293, doi:10.1016/0168-1923(95)02265-Y.

Pereira, A. R. (2004), The Priestley-Taylor parameter and the decoupling factor for estimating reference evapotranspiration, Agricult. Forest Meteorol., 125(3), 305-313, doi:10.1016/j.agrformet.2004.04.002.

Sobrino, J. A., M. Gómez, J. C. Jiménez-Muñoz, and A. Olioso (2007), Application of a simple algorithm to estimate the daily evapotranspiration from NOAA-AVHRR images for the Iberian Peninsula, Remote Sens. Environ., 110, 139-148, doi:10.1016/j.rse.2007.02.017.

$\mathrm{Su}, \mathrm{Z}$. (2002), The Surface Energy Balance System (SEBS) for estimation of turbulent heat fluxes, Hydrol. Earth Syst. Sci., 6 (1), 85-100.

Tang, R. L., Z. -L. Li, and Sun, X (2013), Temporal upscaling of instantaneous evapotranspiration: An intercomparison of four methods using eddy covariance measurements and MODIS data, Remote Sens. Environ. 138, 102-118, doi:10.1016/j.rse.2013.07.001.

Tang, R., Z.-L. Li, Y. Jia, C. Li, X. Sun, W. P. Kustas, and M. C. Anderson (2011), An inter-comparison of three remote sensing-based energy balance models using Large Aperture Scintillometer measurements over a wheat-corn production region, Remote Sens. Environ. 115 (12), 3187-3202, doi:10.1016/j.rse.2011.07.004.

Twine, T. E., W. P. Kustas, J. M. Norman, D. R. Cook, P. R. Houser, T. P. Meyers, J. H. Prueger, P. J. Starks, and M. L. Wesely (2000), Correcting Eddy-Covariance Flux Underestimates over a Grassland, Agricult. Forest Meteorol., 103, 279-300, doi:10.1016/S0168-1923(00)00123-4.

Van Niel, T. G., T. R. McVicar, M. L. Roderick, A. I. Van Dijk, L. J. Renzullo, and E. Van Gorsel (2011), Correcting for systematic error in satellite-derived latent heat flux due to assumptions 
in temporal scaling: Assessment from flux tower observations, J. Hydrol., 409, 140-148, doi:10.1016/j.jhydrol.2011.08.011.

Van Niel, T. G., T. R. McVicar, M. L. Roderick, A. I. Van Dijk, J. Beringer, L. Hutley, and E. Van Gorsel (2012), Upscaling latent heat flux for thermal remote sensing studies: comparison of alternative approaches and correction of bias, J. Hydrol., 468-469, 35-46, doi:10.1016/j.jhydrol.2012.08.005.

Xu, T., S. Liu, L. Xu, Y. Chen, Z. Jia, Z. Xu, and J. Nielson (2015), Temporal upscaling and reconstruction of thermal remotely sensed instantaneous evapotranspiration, Remote Sens. 7, 3400-3425, doi:10.3390/rs70303400. 